\title{
The (first) British Dental Conference and Dentistry Show
}

The British Dental Association (BDA) and CloserStill Media collaborated this year to present the British Dental Conference and Dentistry Show. The new collaboration of the BDA's British Dental Conference and Exhibition, and CloserStill Media's The Dentistry Show took place on 18-19 May 2018. The highly anticipated event welcomed thousands of dental professionals through the doors, attracting all members of the team with its promise of first-class training and free enhanced CPD.

The BDA Theatre hosted particularly impressive speakers renowned throughout the profession including Dr Didier Dietschi, discussing bio-aesthetic smile rehabilitation, and Dr Koray Feran,

discussing how to manage a patient's dental implants that have been placed by someone else.

In Dr Richard Porter's lecture he considered common patient complaints and the need for empathy in a practitioner. He recommended several books for further reading and urged delegates to realise a balance between what's acceptable and what's going too far.

Other sessions in the BDA Theatre saw Dr Tidu Mankoo suggest designing treatment plans for the best possible long-term prognosis and Dr Mark Singh discussing oral cancer, its possible treatment options and their effects on patients. Drs Neik Opdam, Charlotte Stilwell, Bhupinder Dawett and Arshad Ali also all delivered interesting and wellreceived lectures.

Aside from the BDA Theatre, delegates had the opportunity to attend various lectures across the event for even more enhanced CPD. The trade floor also hosted hundreds of dental manufacturers, suppliers and service providers, enabling delegates to network, catch up with friends and colleagues, and discover the latest innovations in the profession.

Susie Sanderson OBE, President of the BDA, commented: 'I thought the event had a great buzz about it and everyone I spoke to seemed to enjoy themselves enormously. This is important for me, as it demonstrates the coming together of dentistry. It's something we previously achieved with the BDA Conference and I'm pleased that it has been perpetuated in the joint event. The collaboration of CloserStill Media and the BDA appeared to be greater than the sum of its parts, so we were really getting the best of both worlds. It was lovely to see the event busy the entire time. I learnt a huge amount from the sessions I chaired in the BDA Theatre, which were all full, with enthusiastic audiences who asked lots of questions.'

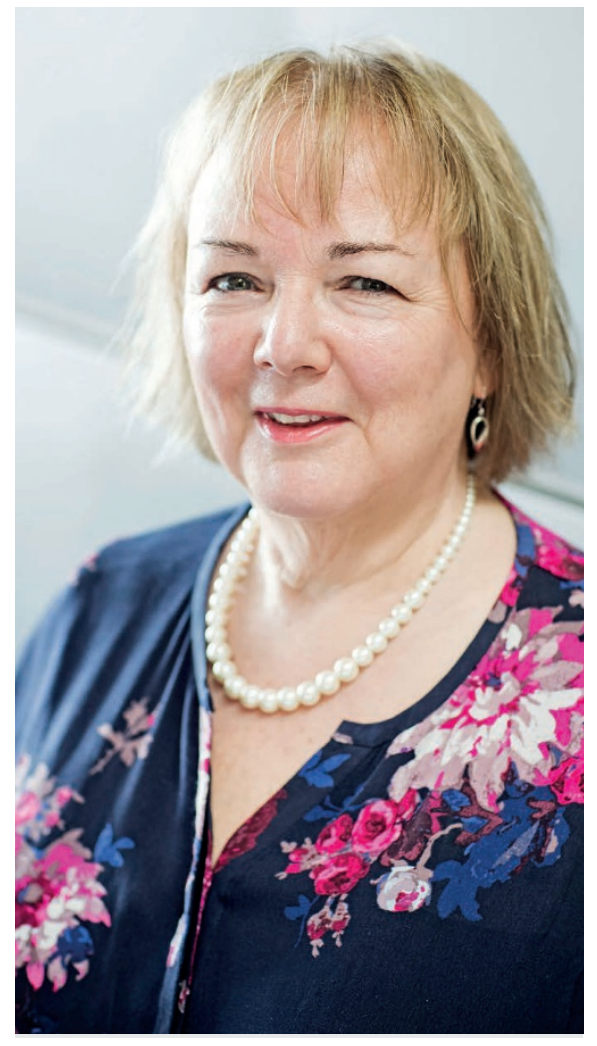

Susie Sanderson, current BDA President

The British Dental Conference and Dentistry Show 2019 will take place from 17-18 May 2019 at Birmingham NEC. For further details visit www.thedentistryshow.co.uk, call 02073485270 or email dentistry@closerstillmedia.com.

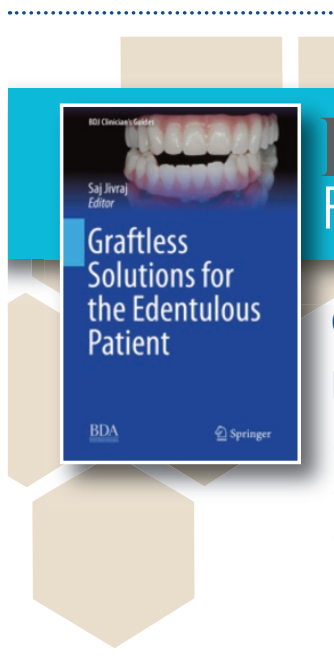

\section{BDJClinicion's Guides Practical - Concise - Accessible}

\section{Graftless Solutions for the Edentulous Patient}

Edited by Saj Jivraj

- Explains the rationale and technique for the rehabilitation of fully edentulous patients

- Covers both traditional graftless concepts and zygomatic implant strategies

- Provides step-by-step descriptions of techniques

434pp I 662 illustrations I Hardcover

Price: $\$ 109.9$ | BDA Member Price: $£ 85.24$

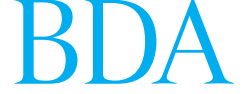

British Dental Association
HOW TO ORDER Buy now from shop.bda.org/graftless-solutions BDA Members save over 20\%. Free P\&P for BDA members 